\title{
Key lessons from the implementation of ERP in Canada
}

\author{
Armin Jabbarzadeh ${ }^{\mathbf{a}^{*}}$
}

${ }^{a}$ Business School, McMaster University, Ontario, Canada

\begin{tabular}{l}
\hline C H R O N I C L E \\
\hline Article history: \\
Received: October 1, 2017 \\
Received in revised format: No- \\
vember 16, 2017 \\
Accepted: May 17, 2018 \\
Available online: \\
May 17, 2018 \\
\hline Keywords: \\
Enterprise resource planning \\
Logistics \\
Canada
\end{tabular}

\section{A B S T R A C T}

\begin{abstract}
Enterprise resource planning (ERP) is the integrated management of core business processes, often in real-time and mediated by software and technology. ERP gives us an integrated and updated image of core business processes based on common databases retained by a database management system. ERP systems are able to track business resources including cash, raw materials, production capacity and the status of business commitments such as orders, purchase orders, and payroll. This paper presents different experiences of the implementation of ERP in Canada.
\end{abstract}

C 2017 by the ayhors, licensee Growing Science, Canada.

\section{Introduction}

Enterprise resource planning (ERP) is the integrated management of core business processes, often in real-time and mediated by software and technology. ERP gives us an integrated and updated image of core business processes based on common databases retained by a database management system. ERP systems are able to track business resources including cash, raw materials, production capacity and the status of business commitments such as orders, purchase orders, and payroll (Daneva, 2006). ERP software packages are relatively expensive and produces components supporting different business functions. Information technology (IT) investments have become the biggest category of capital cost in North America during the past decade. The implementation of ERP normally costs significantly but in many cases, the outcome ends with failure (Poti et al., 2011; Michalak \& Jones, 2003). There are many reasons for this such as feeling insecurity of the employees, unfamiliarity of staff on ERP implementation, etc. Fig. 1 shows different components of ERP in any business unit. According to Fig. 1, several departments need to cooperate with each other to reach a successful ERP and any disruption could end up with unpleasant consequences.

* Corresponding author.

E-mail address: Jabbarza@mcmaster.ca (A. Jabbarzadeh) 


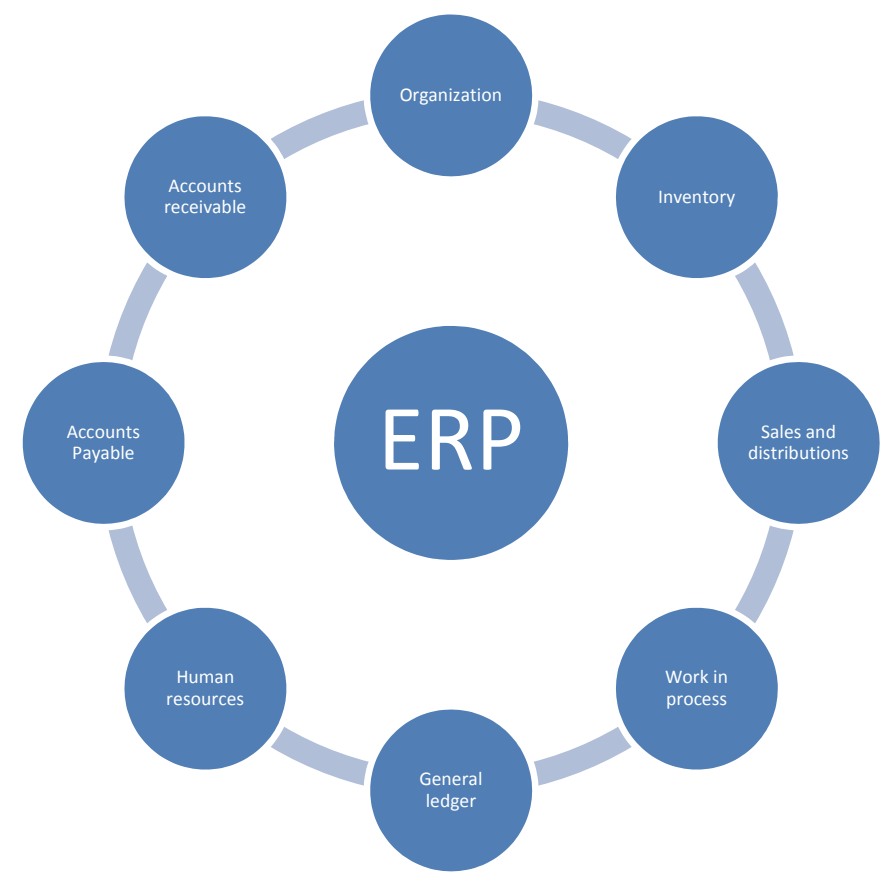

Fig. 1. Different components of ERP

The (ERP) system can integrate the major business management functions of the enterprise with a single common database to allow sharing of all information and achieve efficient communications between management functions (Lee et al., 2004). Based on the requirements of running a construction enterprise, ERP represents potential applicability for the construction industry. Lee et al. (2004) investigated the advantages of ERP systems when applied to construction materials procurement. They explained the business processes engaged in construction materials procurement and demonstrated how ERP systems would be applied and the efficiency of the construction materials management system consequently enhanced.

In this survey, we present some of the recent experiences on the ERP usage in Canada. The study covers the effects of rules and regulations in Canada on ERP implementation in Canada.

\section{ERP implementation in small and medium enterprises}

Tchokogué et al. (2005) applied a case study to learn some lessons from a successful implementation of an ERP system. It pointed out some strategic, tactic and operational considerations inherent in an ERP implementation that are needed to effective organizational transformation required by a system implementation such as SAP R/3. At the strategic level, top managers built a clear vision of the role of the ERP project in their business model, along with P \& WC's strategic priority. They built a feeling of urgency, and determined the scope and scale of the project. Top management thus committed significant resources by assigning sufficient human and financial resources and retained in backing a structured and disciplined method for the implementation until completion of the project. The effect of the ERP system on employees was investigated comprehensively and integrated in the action strategies. A massive training program was deployed using many of P \& WC's own employees as instructors to ensure a good appropriation of the technology. They provided a successful experience for the ERP implementation. 


\section{ERP implementation for improvement in accounting system}

Sánchez-Rodríguez and Spraakman (2012) performed an investigation to find the effect of ERP on management accounting by analyzing the changes that ERP implementations had on performance measures, management accounting techniques, activities of management accountants, and the use of non-financial information. They interviewed 13 major Canadian firms as part of a multiple case study and using open-ended questions methods. The study studied how ERP use through more computational power, relational databases, standardized state-of-the-art transaction processing, and extended chart of accounts change management accounting. The study provided some insights for understanding how ERP systems could influence on management accounting and management accountants.

Kumar et al. (2008) examined different challenges encountered by firms in enhancing their ERP systems for compliance with regulatory internal control needs, specifically those imposed by the Canadian legislation. They collected the necessary data through case studies of four medium-sized and large companies that apply ERP systems and that have operations in the USA and Canada. The firms encountered some technical, process and cultural challenges in using regulatory control compliance. In all firms, existing ERP systems were not capable of meeting all control requirements without some modifications or add-on applications. Control implementations have been long, complicated with expensive process, which were not fully completed. Detailed analyses and documentation of existing systems, controls and processes were needed in all firms. The protection of systems security and the integration of responsibilities were considered to be major technical barriers. Cultural factors yielded in more challenges, resistance to change.

\section{Conclusion}

This paper has presented an overview of the experiences of the implementation of ERP in Canadian business corporations. The study has shown that rules and regulations may influence significantly on the adaptation of ERP. ERP could fail in organizations when employees are not familiar with details of the implementation of different software packages in the system. The other important issue is that ERP usage could result to having fewer number of employees and therefore, present employees may resist to share information to start the ERP projects.

\section{References}

Daneva, M. (2006, June). Integrating reuse measurement practices into the ERP requirements engineering process. In International Conference on Product Focused Software Process Improvement (pp. 112-126). Springer, Berlin, Heidelberg.

Kumar, V., Pollanen, R., \& Maheshwari, B. (2008). Challenges in enhancing enterprise resource planning systems for compliance with Sarbanes-Oxley Act and analogous Canadian legislation. Management Research News, 31(10), 758-773.

Lee, S., Arif, A. U., \& Jang, H. (2004). Quantified benefit of implementing enterprise resource planning through process simulation. Canadian Journal of Civil Engineering, 31(2), 263-271.

Michalak, W., \& Jones, K. (2003). Canadian e-commerce. International Journal of Retail \& Distribution Management, 31(1), 5-15.

Poti, S., Bhattacharyya, S., \& Kamalanabhan, T. J. (2011). Social and cultural challenges in ERP implementation: a comparative study across countries and cultures. International Journal of Information Systems and Social Change (IJISSC), 2(4), 44-67.

Sánchez-Rodríguez, C., \& Spraakman, G. (2012). ERP systems and management accounting: A multiple case study. Qualitative Research in Accounting \& Management, 9(4), 398-414.

Tchokogué, A., Bareil, C., \& Duguay, C. R. (2005). Key lessons from the implementation of an ERP at Pratt \& Whitney Canada. International Journal of Production Economics, 95(2), 151-163. 
(C) 2017 by the authors; licensee Growing Science, Canada. This is an open access article distributed under the terms and conditions of the Creative Commons Attribution (CC-BY) license (http://creativecommons.org/licenses/by/4.0/). 